\title{
REVIEW
}

\section{What is the Urinary Diversion of Choice after Cystectomy in 2020?}

\author{
Youssef Kharbach a (iD, Abdelhak Khallouk ${ }^{b}$ \\ ${ }^{a} \mathrm{MD}$, Urology assistant professor, Urology department, Tangier University Hospital, Faculty of Medicine, \\ Abdelmalek Essaâdi University, 90000 Tangier, Morocco \\ ${ }^{\mathrm{b}} \mathrm{MD}$, Urology professor, Urology department, Tangier University Hospital, Faculty of Medicine, \\ Abdelmalek Essaâdi University, 90000 Tangier, Morocco
}

\begin{abstract}
Urinary diversion is often indicated after radical cystectomy for bladder cancer. It can either be non-continent or continent. Ileal conduit and orthotopic urinary diversions (neobladder) are by far the most commonly used diversions. The choice of the urinary diversion to be carried out is done on several levels in relation to the underlying disease, the state of the patient and the surgeon preference. It is inappropriate to make direct comparisons between enterocystoplasty and ileal conduit because of the differences in the choice of patients for each technique making a prospective randomized trial unlikely. The choice of the technique must be made after clearly informing and explaining explaining to the patient to enable him accept and adapt to his urinary diversion.
\end{abstract}

KEYWORDS: Cystectomy ; Urinary Diversion ; Ileal Conduit ; Neobladder ; Decision-Making.

Correspondence: Dr Youssef Kharbach, Urology department, Mohammed VI Hospital, Avenue Martyr El Alami Taghzouti, 90000 Tangier, Morocco. Email: ykharbach@uae.ac.ma

Copyright $\odot 2020$ Kharbach Y \& Khallouk A. This is an open access article distributed under the Creative Commons Attribution 4.0 International, which permits unrestricted use, distribution, and reproduction in any medium, provided the original work is properly cited.

\section{INTRODUCTION}

Urinary diversion is often indicated after radical cystectomy for bladder cancer. It can either be noncontinent or continent. The choice of the technique must be made after clearly informing and explaining explaining to the patient to enable him accept and adapt to his urinary diversion after surgery as it will influence the patient's quality of life. This article is an update on published data on urinary diversions.

\section{THE PRINCIPLES OF URINARY DIVERSION PROCEDURES}

a. Non-continent urinary diversion

- Bilateral cutaneous ureterostomy requires fitting on each side of the abdomen and the maintenance of a ureteral catheter to prevent stenosis of ureterocutaneous anastomosis [1]. This type of urinary diversion avoids gastro-intestinal complications as the digestive tract is not used. This makes this technique a strategic choice for elderly or frail patients [1].

- Ileal conduit has the advantage of avoiding keeping ureteral catheters in place and creating a single stoma orifice [1]. This has made this technique the most widely used on a global scale [1,2]. On the other hand, it can be responsible for gastro-intestinal complications such as : prolonged ileus, fistula and / or anastomotic stenosis [1].
In order to optimize this diversion, it will be necessary to respect certain recommendations [1,3] i.e:

i. Avoid placing the stoma below the belt line.

ii. Avoid placing the stoma on a fold or in a deep skin crease

iii. Atraumatic passage through the muscular wall

iv. Hem the intestinal mucosa at the level of the stoma

b. Continent Urinary diversion

- Could be heterotopic (ileocolic pouch by Koch or Mainz) or orthotopic (enterocystoplasty: neobladder by Hautmann, Studer or Foch)[1].

- Enterocystoplasty allows continent urinary diversion but requires rehabilitation in order to guarantee satisfactory continence and bladder voiding [1].

Ileal conduit and orthotopic urinary diversions (neobladder) are by far the most commonly used diversions [4]. The morbidity and mortality related to these two techniques are comparable [4,5].

It should be mentioned that ileal conduit and orthotopic urinary diversions (neobladder) are by far the most commonly used diversions.

\section{THE CHOICE CRITERIA}

The choice of the urinary diversion to be carried out is done on several levels

a. In relation to the underlying disease 
Urinary diversions are performed after cystectomy. Among the numerous indications for urinary diversion, radical treatment for bladder cancer most often requires this procedure [1]. Enterocystoplasty requires an intact ureter (confirmed by cystoscopy or by extemporaneous examination of a sample taken from the urethral stump) and a non-locally advanced tumor (T3b-T4 and or $\mathrm{N}+$ ). Non-continent diversions will be indicated in cases other than the above listed criteria [1].

\section{b. In relation to the state of the patient}

Enterocystoplasty requires a good general health and cognitive conditions that will enable the patient to perform muscular exercises or self-catheterizations [1] to facilitate bladder voiding and the continence bladder [6].

In addition to these factors, a good kidney function with a glomerular filtration rate $>50 \mathrm{~mL} / \mathrm{min}$ [7] is required. Contradictive factors for enterocystoplasty are inflammatory bowel diseases, past history of pelvic irradiation at high doses $[1,7]$.

Older, less educated, or significantly co-morbid patients are less likely to benefit from continent diversions $[5,8]$.

c. In relation to the patient's choice:

The respect of the natural anatomy of the human body is often questioned by the patient during preoperative consultations with the surgeon. Tao [9] has demonstrated the complexity and diversity of patients living with an ostomy as well as decreased self-esteem in some cases. The lack of sufficient pre- and postoperative counselling was generally mentioned by ostomates as the main health care problem $[9,10]$. The choice of noncontinent diversion would be more acceptable for patients who are less active than sports patients [11]. Optimal management is therefore based on an understanding of patients' perceptions and their context of life [11], which implies multidisciplinary care [9]. It is also important to explain to patients who are candidates for enterocystoplasty that they may require the use of perineal rehabilitation $[1,12]$ as there is the possibility of developing postoperative urinary incontinence which is a therapeutic risk. The patient may or may not readily accept enterocystoplasty due to the risk of having an altered the quality of life.

\section{d. In relation to the surgeon:}

There is great variability in the choice of the preferred urinary diversion between hospitals and even surgeons in the same center [13]. The probability of having a neobladder in notable oncology centers is $30 \%$ to $45 \%$. This may rise to $75 \%$ in pioneer institutions [13]. The majority of surgeons prefer an ileal conduit for various reasons: insufficient experience in enterocystoplasty, the fear of postoperative complications or the high medical bills related with continent diversions [14]. These factors may influence how the surgeon counsels his patients on the pros and cons of each urinary diversion. Thus, influencing the patients' final choice.

The International Consultation on Bladder CancerEuropean Association of Urology (ICUD-EAU) strongly recommends that the realization of radical cystectomy with urinary diversion should be carried out in hospitals where at least 40 to 50 interventions per year are carried out, of which half of these procedures will be performed. by one or two surgeons, in order to guarantee their expertise, the availability of a well-trained staff and minimum of long-term complications [5,15-17]. In addition, procedures performed at a non-university hospital center have more readmission rates of patients within 30 days after surgery [4].

Moreover, the American series of Maurice et al. [2] showed that the socio-economic status of patients was an independent predictor of the type of urinary diversion proposed to patients. In fact, surgeons tend to offer continent urinary diversions to high-income patients, whereas low-income patients were offered a non-continent urinary diversion [2].

\section{DECISION / CHOICE}

When the state of the patient and the nature of the underlying pathology make it possible to propose several urinary diversions, the patient should benefit from a clear and precise information on each surgical technique as well as its complications. As long as there is no evidence of the superiority of one technique over another in the literature [1], the patient should have the chance to choose the urinary diversion that suits him or her. However, the managing team should offer the techniques it has competence in so as to ensure that the patient has the best possible outcome [18].

\section{QUALITY OF LIFE: ENTEROCYSTOPLASTY OR ILEAL CONDUIT?}

It would be inappropriate to make direct comparisons between enterocystoplasty and ileal conduit because of the differences in the choice of patients for each technique making a prospective randomized trial unlikely [15]. Nevertheless, we have found four meta-analysis that have addressed this issue [20-23]:

- In the meta-analysis of Yang et al. [20] on 29 studies and Porter et al. [21] on 15 studies, the conclusion was that there was no difference in quality of life between the two diversion techniques.

- The meta-analysis of Cerruto et al. on 18 studies showed that patients with enterocystoplasty had a better quality of life [22].

- On the other hand, Ziouziou et al. on four studies concluded that patients having ileal conduit had better quality of life [23].

\section{WHAT IS THE URINARY DIVERSION OF CHOICE IN 2020?}

The French association of urology prefers replacement enterocystoplasty in the absence of contraindications. Ileal conduit is offered in other cases. Bilateral cutaneous ureterostomy should be avoided and indicated only in palliative cystectomies or in cases where other urinary diversions are impossible to perform [7].

The European Association of Urology recommends that replacement enterocystoplasty should not be performed in case of a positive urethral margin, if the tumor is located in the cervix (in women) or in the prostate (in men)[24].

The American Urology Association recommends a clear explanation of all possible urinary derivations for the patient. However, a negative urethral margin is mandatory in the case of replacement enterocystoplasty [25].

\section{CONCLUSION}

It seems judicious to base the choice of the diversion technique first on the expertise of the surgical team. However, the choice of urinary diversion must be decided in consultation with the patient to suit his or her general and functional state as well as to his or her way of life. 


\section{ETHICS APPROVAL AND CONSENT TO PARTICIPATE}

Not applicable

\section{CONSENT FOR PUBLICATION}

Not applicable

\section{AVAILABILITY OF DATA AND MATERIALS}

Not applicable.

\section{COMPETING INTERESTS}

The authors declare that there is no conflict of interest.

\section{REFERENCES}

[1] Neuzillet Y, Rouprêt M; les membres du sous-comité vessie du CCAFU. Quality of life of patients carrying an urinary diversion. Prog Urol. 2017;27(14):845-50.

[2] Maurice MJ, Kim SP, Abouassaly R. Socioeconomic status is associated with urinary diversion utilization after radical cystectomy for bladder cancer. Int Urol Nephrol. 2017;49(1):77-82.

[3] Salvadalena G, Hendren S, McKenna L, Muldoon R, Netsch D, Paquette I et al. WOCN Society and AUA Position statement on preoperative stoma site marking for patients undergoing urostomy surgery. J Wound Ostomy Continence Nurs. 2015;42(3):253-6.

[4] Nahar B, Koru-Sengul T, Miao F, Prakash NS, Venkatramani V, Gauri A et al. Comparison of readmission and short-term mortality rates between different types of urinary diversion in patients undergoing radical cystectomy. World J Urol. 2018;36(3):393-9.

[5] Gore JL, Saigal CS, Hanley JM, Schonlau M, Litwin MS. Urologic diseases in america project variations in reconstruction after radical cystectomy. Cancer. 2006;107(4):729-37.

[6] Hautmann RE, de Petriconi RC, Pfeiffer C, Volkmer BG. Radical cystectomy for urothelial carcinoma of the bladder without neoadjuvant or adjuvant therapy: long-term results in 1100 patients. Eur Urol. 2012;61(5):1039-47.

[7] Rouprêt M, Neuzillet Y, Pignot G, Compérat E, Audenet F, Houédé $\mathrm{N}$ et al. Recommandations françaises du Comité de Cancérologie de l'AFU - Actualisation 2018-2020: tumeurs de la vessie French ccAFU guidelines - Update 2018-2020: Bladder cancer. Prog Urol. 2018;28(12S):S46-S78.

[8] Luchey AM, Agarwal G, Espiritu PN, Lockhart JL, PowSang JM, Spiess PE et al. Patient and disease-specific factors and their influence on urinary reconstruction choice at a referral center. World J Urol. 2015;33(11):1763-8.

[9] Tao H, Songwathana P, Isaramalai SA, Zhang Y. Personal awareness and behavioural choices on having a stoma: a qualitative metasynthesis. J Clin Nurs. 2014;23(910):1186-200.

[10] Barnabe NC, Dell'acqua MC. Coping strategies of ostomized individuals. Rev Lat Am Enfermagem. 2008;16(4):712-9.

[11] Engebretson JC, Headley JA (2009). Cultural diversity and care. In Holistic Nursing: A Handbook for Practice. (Dossey BM \& Keegan L eds). Jones and Bartlett Publishers, Sudbury, MA; 2009.

[12] Lee RK, Abol-Enein H, Artibani W, Bochner B, Dalbagni $\mathrm{G}$, Daneshmand $\mathrm{S}$ et al. Urinary diversion after radical cystectomy for bladder cancer: options, patient selection, and outcomes. BJU Int. 2014;113(1):11-23.

[13] Hautmann RE, Abol-Enein H, Lee CT, Mansson W, Mills RD, Penson DF. Urinary diversion: how experts divert. Urology. 2015;85(1):233-8.

\section{FUNDING}

This research received no specific grant from any funding agency in the public, commercial, or not-for-profit sectors.

\section{AUTHORS' CONTRIBUTIONS:}

Both YK researched the literature and analysed the current evidence. YK prepared the first draft of the manuscript. AK reviewed the manuscript. Both authors approved the final version of the manuscript.

\section{ACKNOWLEDGEMENTS}

None

[14] Skinner EC. Choosing the right urinary diversion: patient's choice or surgeon's inclination? Urol Oncol. 2011;29(5):473-5.

[15] Hautmann RE, Abol-Enein H, Davidsson T, Gudjonsson S, Hautmann SH, Holm HV et al. ICUD-EAU International Consultation on Bladder Cancer 2012: Urinary diversion. Eur Urol. 2013;63(1):67-80.

[16] Hautmann RE. Declining use of orthotopic reconstruction worldwide-what went wrong? J Urol. 2018;199(4):900-3.

[17] Kwan ML, Leo MC, Danforth KN, Weinmann S, Lee VS, Munneke JR et al. Factors that influence selection of urinary diversion among bladder cancer patients in 3 community-based integrated health care systems. Urology. 2019;125:222-9.

[18] Goossens-Laan CA, Gooiker GA, van Gijn W, Post PN, Bosch JL, Kil PJ et al. A systematic review and metaanalysis of the relationship between hospital/surgeon volume and outcome for radical cystectomy: an update for the ongoing debate. Eur Urol. 2011;59(5):775-83.

[19] Colwell JC, Gray M. Does preoperative teaching and stoma site marking affect surgical outcomes in patients undergoing ostomy surgery? J Wound Ostomy Continence Nurs. 2007;34(5):492-6.

[20] Yang LS, Shan BL, Shan LL, Chin P, Murray S, Ahmadi $\mathrm{N}$ et al. A systematic review and meta-analysis of quality of life outcomes after radical cystectomy for bladder cancer. Surg Oncol. 2016;25(3):281-97.

[21] Porter MP, Penson DF. Health related quality of life after radical cystectomy and urinary diversion for bladder cancer: a systematic review and critical analysis of the literature. J Urol. 2005;173(4):1318-22.

[22] Cerruto MA, D'Elia C, Siracusano S, Gedeshi X, Mariotto A, Iafrate $M$ et al. Systematic review and meta-analysis of non RCT's on health related quality of life after radical cystectomy using validated questionnaires: Better results with orthotopic neobladder versus ileal conduit. Eur J Surg Oncol. 2016;42(3):343-60

[23] Ziouziou I, Irani J, Wei JT, Karmouni T, El Khader K, Koutani A et al. Ileal conduit vs orthotopic neobladder: Which one offers the best health-related quality of life in patients undergoing radical cystectomy? A systematic review of literature and meta-analysis. Prog Urol. 2018;28(5):241-50.

[24] Witjes JA, Bruins M, Cathomas R, Compérat E, Cowan $\mathrm{NC}$, Gakis $\mathrm{G}$ et al. EAU guidelines on muscle-invasive and metastatic bladder cancer. EAU Guidelines. Edn. presented at the EAU Annual Congress Barcelona 2019. ISBN 978 94-92671-04-2. EAU Guidelines Office, Arnhem, The Netherlands.

[25] Chang SS, Boorjian SA, Chou R, Clark PE, Daneshmand S, Konety BR. Diagnosis and Treatment of Non-Muscle Invasive Bladder Cancer: AUA/SUO Guideline. J Urol. 2016. J Urol 2016;196(4):1021-9. 